Original Article

\title{
Lower Third M olar Space and Angulation in Individuals with Lower Anterior Crowding
}

\section{Merin Cherian ${ }^{1}$, M.S. Ravi ${ }^{2}$}

${ }^{1}$ BDS, ${ }^{2}$ MDS, ${ }^{1}$ Post Graduate, ${ }^{2}$ Professor and Head, Dept. of Orthodontics, A.B. Shetty Memorial Institute of Dental Sciences, Nitte University, Mangalore.

*Corresponding Author : M. S. Ravi, M DS, Professor and Head, Dept. of Orthodontics, A.B. Shetty M emorial Institute of Dental Sciences, Nitte University, Mangalore - 575 018. Fax: +918242204776.

Received : :23-02-2016

Review Completed : 13-06-2016

Accepted

28-06-2016

Keywords : Third molar space, Third molar angulation, Lower a n t erior crow ding, Orthopantomograph.

\begin{tabular}{|c|}
\hline Access this article online \\
\hline Quick Response Code \\
\hline
\end{tabular}

\begin{abstract}
:
Background: The role and involvement of mandibular third molars on mandibular incisor crowding, post retention, in orthodontically treated patients has long been debated. The correlations between lower anterior crowding and lower third molar angulation and space are not completely understood.
\end{abstract}

Aim: To assess the lower third molar space and its angulation in individuals with lower anterior crowding and to compare it with that of individuals without lower anterior crowding.

Settings and design: Hospital based Prospective, cross-sectional study on randomly selected individuals.

Materials and Methods: Lower third molar space and angulations were measured and compared using orthopantomograph tracings of 80 subjects in the age group of 20-30 years with skeletal Class I malocclusion individuals without lower anterior crowding(Group A) and individuals with lower anterior crowding (Group B)

Statistical Analysis: Both the space and angulations of lower third molar were correlated with the lower anterior crowding using Pearson Correlation Coefficient.

Results: Significant differences were found in third molar space between the study group and the control group. But there wasno significant difference in third molar angulation between the groups.

Conclusion: the lower anterior crowding has a significant influence on third molar space but did not have any effect on third molar angulation.

\section{Introduction}

The mandibular incisor crowding is a well-known problem, the cause of which has been the substance of considerable debate over the years. Mandibular anterior crowding occurs as a result of disparity between the tooth size of anterior teeth and available space in the alveolar process which results in abnormal angulations and rotations of teeth. One possible factor is that it is manifested as the pressure from third molars. Third molars have been one of the most controversial subject regarding the cause for incisor crow ding. ${ }^{1}$

The anterior arch crowding increases the chances of having third molar impacted because of lack of space for their eruption. The initial angulations of third molars may also influence their subsequent eruption. ${ }^{2}$

It is said that the erupting third molars push anterior teeth forward and cause anterior crowding. It is also established that the dental arch length reduces between the age 12 years and 25 years. ${ }^{5}$

In order to prevent lower third molar impactions it is necessary to identify when impactions are likely to occur. Various methods have been used in the past. Ganss presented a method where third molar impactions could be predicted from the third molar space on orthopantomograph which was a modification of Olive and Basford's method. This may provide information regarding future development of dental arch crowding and 
indications for third molar removal. ${ }^{8}$

Evidence supports that the treatment for asymptomatic, pathology free third molar impaction is observation instead of prophylactic removal to prevent late lower crowding in untreated individuals or post retention crowding. ${ }^{9}$

Also some studies have shown that when third molar angulation increases, the risk of impaction increases which may be explained by the small mandibular length in subjects that may have limited the up-righting of third molars during development. ${ }^{3}$

Hence this study was designed to measure mandibular third molar space and its angulation in individuals with anterior crowding, and compare them with the individuals without lower anterior crowding. The findings of the study would help us to understand the correlation between lower anterior crowding and lower third molar angulation and space.

\section{Materials and Methods}

A total of 80 individuals in the age group of 20-30 years who had given their written informed consent to participate in the study were selected and were classified into following two groups.

Group A: The control group included 40 individuals (20 males, 20 females) without lower anterior crowding.

Group B: The study group included 40 individuals (20 males, 20 females) with lower anterior crowding of atleast $4 \mathrm{~mm}$ as measured by Little's Index. ${ }^{4}$

\section{Inclusion criteria:}

- Skeletal Class I maxilla-mandible relationship as decided by angles SNA, SNB and ANB in lateral cephalogram.

- Full complement of teeth, irrespective of the third molars.

- M inimal loss of tooth dimension by caries or attrition.

- Presence of crowding of more than $4 \mathrm{~mm}$ in the mandibular anterior region, as measured by Little's index of irregularity, for individuals in study group. ${ }^{4}$

\section{Exclusion criteria}

- Presence of retained deciduous teeth, supernumerary teeth etc.

- Presence of mandible asymmetries.

- Presence of large restorations, artificial teeth.

- Presence of skeletal disorders and abnormalities.

- Individuals who have had prior orthodontic treatment or orthognathic surgery.

- Individuals who were not willing to take part in the study.

\section{Methodology}

After the study was approved by the Institutional Ethics Committee; Orthopantomographs and Lateral Cephalograms were made for all individuals in a standard technique using Planmeca PM 2002 cc Proline (Planmeca, Helsinki, Finland) radiographic machine. Lateral cephalometric analysis of SNA, SNB \& ANB angles were carried out and individuals having Class I skeletal relationships were selected for the study.

\section{Assessment of third molar space and angulation in OPG:}

Areas of third molar tooth, the second molar tooth, the anterior border of ramus were traced on 0.003 -inch matte acetate with a $0.5 \mathrm{~mm}$ diameter lead pencil.

The same operator did all tracings in order to avoid interoperatorerrors.

1. Available space (Figl) was measured between the distal margin of second molar crown and anterior border of ramus on the occlusal plane, shown as Red line $A$.

2. Measurement of third molar crown width represented as Yellow line B.

3. The ratio of line A to line B indicated as Ganss ratio.

4. Third molar angulation was evaluated according to the modification of winter's classification. It describes four types of third molar angulations.

- Mesio-angular: angled in toward the other teeth (Fig 2).

- Disto-angular: angled away from the other teeth (Fig 3).

- Horizontal: parallel to the gum line (Fig 4).

- Vertical: straight upward (Fig5). 


\section{Statistical Analysis}

All statistical analyses were performed using the SPSS software package (SPSS for Windows Xp, version 13.0, SPSS Inc, and Chicago). Data that included arithmetic mean, standard deviation and range values were calculated for each variable as well as for each group and were used for analyses. Pearson Correlation Coefficient was used to find the correlation between the third molar space and crowding and also find correlation between third molar angulation and crowding. $P<0.05$ was considered as significant.

\section{Results}

The present study was carried out in subjects in the age group of 20-30 years with a mean age of 22.5 years. The control group consisted of 40 individuals without lower anterior crowding. The study group consisted of 40 individuals with lower anterior crowding of more than $4 \mathrm{~mm}$. The mean crowding was $7.15 \mathrm{~mm}$.

The mean and standard deviation of mandibular third molar space and its angulation with lower anterior crowding were calculated and compared it with individuals without lower anterior crowding. In the whole sample correlation was done by Pearson Correlation Coefficient.

The mean and the standard deviation of third molar space on both right and left side were calculated. It was found that the study group showed less third molar space compared to that of the control group when both right and left sides were assessed (Table 1),(Graph 1).

Significant difference between the groups relative to third molar space was observed and it was found that the third molar space showed negative correlation with the crowding on both right and left sides (Table 2).

When third molar angulation was assessed there was no significant difference on the right side between the study group and the control group. But the incidence of horizontal angulation was more in the study group (12.5\%) than in the control group (2.5\%). (Table 3), (Graph 2).

Although the mean third molar angulation on right side for the control grouphas shown highest incidence of vertical impaction (60\%), significant difference was not seen when compared with the study group (55\%) (Table 3) (Graph 2).

Again the mean third molar angulation on right side for the control group showed highest incidence of mesioangular impaction (35\%). But significant difference was not seen when compared with the study group (32.5\%) (Table 3) (Graph 2).

Similarly, third molar angulation on the left side was assessed. Again there was no significant difference between the study group and the control group. But the horizontal angulation was more in the study group (20\%) compared with control group (2.5\%) (Table 4) (Graph 3).

Again the mean value of third molar angulation on left side for the control group showed highest incidence of vertical impaction (57.5\%), significant difference was not seen when compared with the study group (52.5\%) (Table 4) (Graph 3).

Again the mean value of third molar angulation on left side for the control group showed highest incidence of mesioangular impaction (37.5\%), significant difference was not seen when compared with the study group (27.5\%) (Table 4) (Graph 3)

The incidence of distoangular impaction both on the right and left sides were very less. It was seen only in the control group (Group A) with $2.5 \%$ and no incidence in the study group (Graph 2 and 3).

\section{Discussion}

This investigation was carried out with the objective of assessing the space and angulations of lower third molars in individuals with lower anterior crowding and comparing with that of individuals without lower anterior crowding.

The subjects in this study were in the age group of 20-30 years with a mean age of 22.5 years. This is the time period when the third molar is fully developed and undergone important rotational movements. ${ }^{6,11,15,29}$ Hence individuals of this age group were selected to see if the third molar had any effect on lower incisor crowding and vice versa. 
Figure 1 : Third molar space measurement.

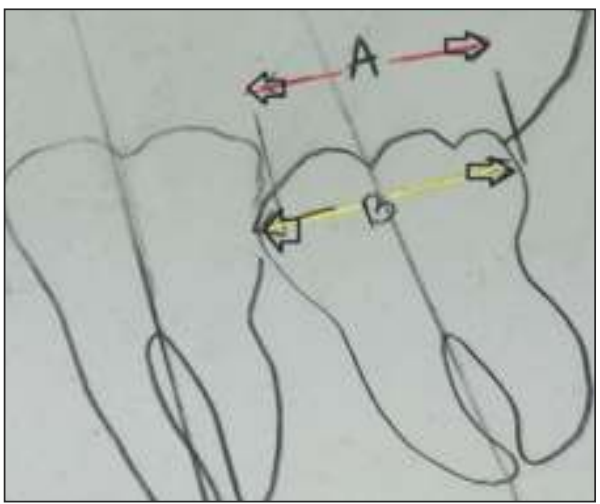

Figure 3 : Distoangular angulationof third molar

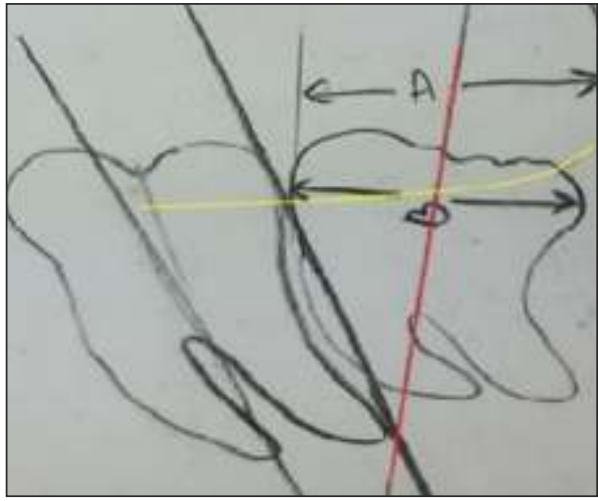

Figure 5 : Vertical angulationof third molar

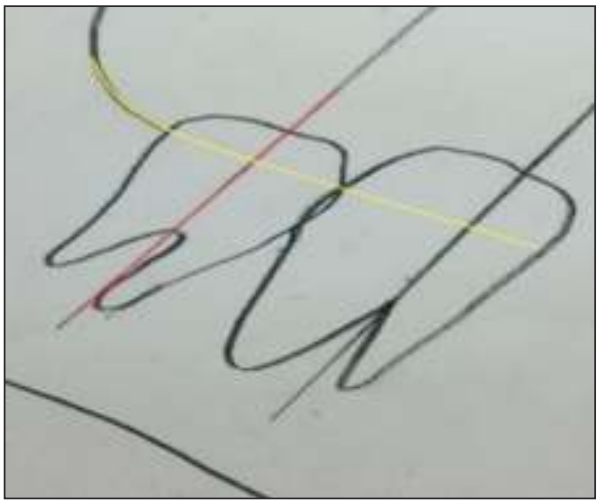

Graph 2 : Comparison of third molar angulation between the groups on the right side (tmangrt).

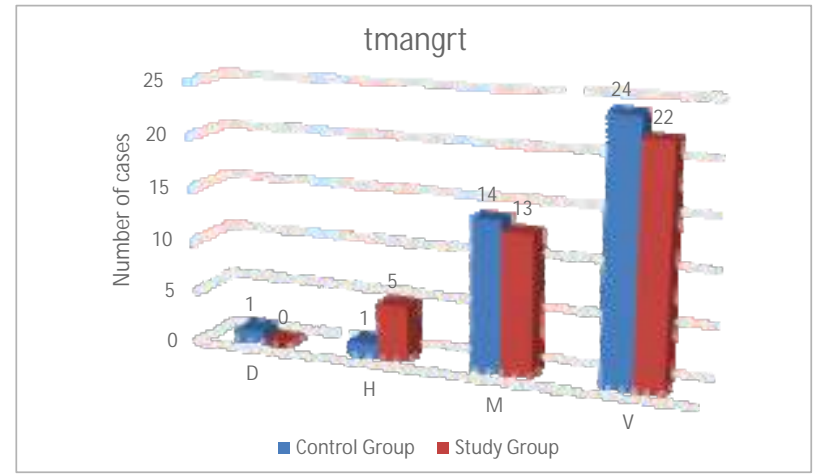

\section{Figure 2 : Mesioangular angulation of third molar}

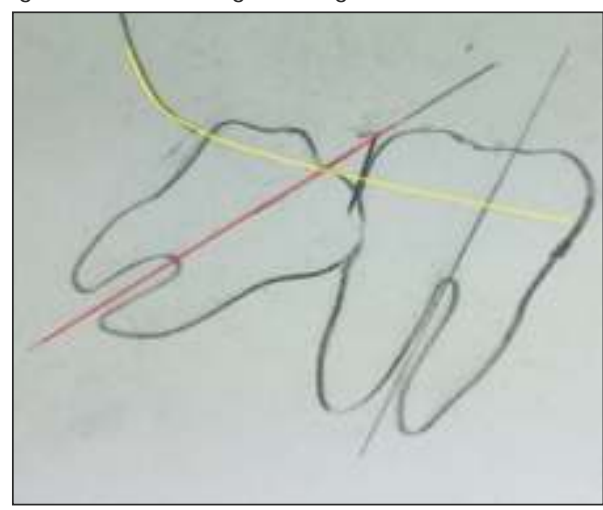

Figure 4 : Horizontal angulationof third molar

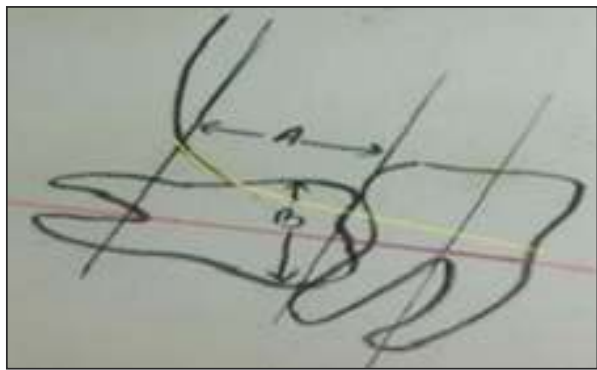

Graph 1 : Comparison of third molar space (TMS) between the groups (Right and Left sides)

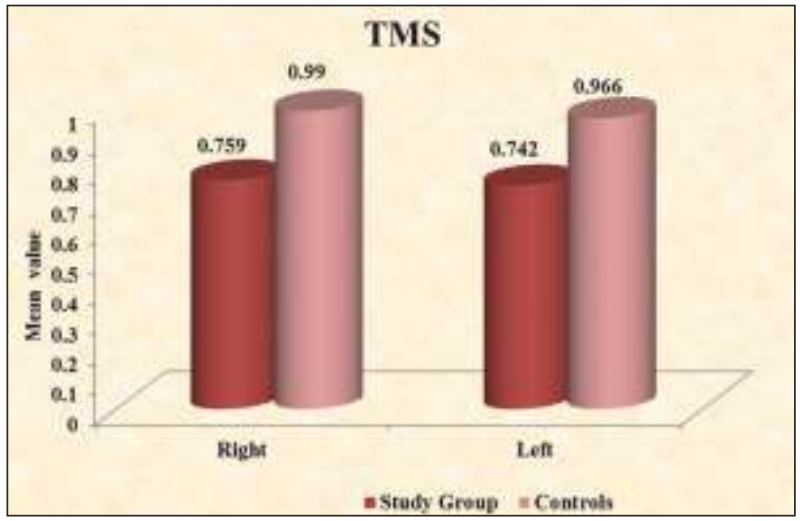

Graph 3 : Comparison of third molar angulation between the groups on the left side (tmanglt).

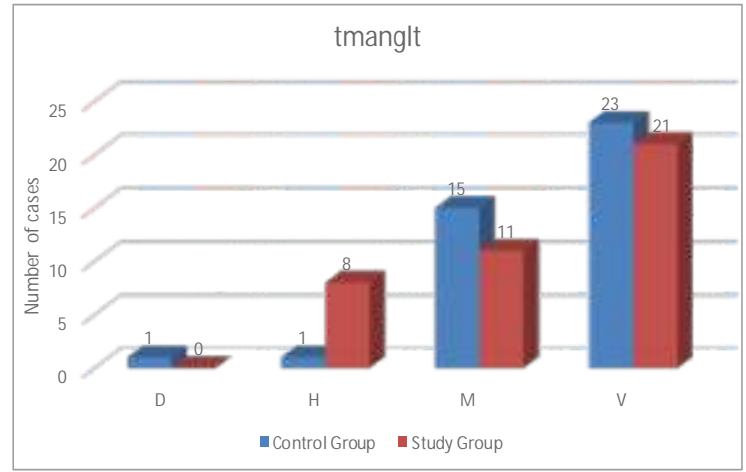


Table 1 : Assessment of third molar space (tms) between the groups on both right (tmsrt) and left (tmslt) sides

\begin{tabular}{|l|c|c|c|}
\hline Third molar space & Group & Mean & Std. deviation \\
\hline \multirow{3}{*}{ Tmsrt } & Control group & 0.990 & 0.267 \\
\cline { 2 - 4 } & Study group & 0.759 & 0.329 \\
\hline \multirow{2}{*}{ TmsIt } & Control group & 0.966 & 0.313 \\
\cline { 2 - 4 } & Study group & 0.742 & 0.380 \\
\hline
\end{tabular}

Table 2: Correlation of third molar space (tms) between the study group and the control group on both right (tmsrt) and left (tmslt) sides.

\begin{tabular}{|c|c|c|}
\hline correlations & Tmsrt & Tmslt \\
\hline R & -0.253 & -0.147 \\
\hline P & 0.115 & 0.366 \\
\hline N & 40 & 40 \\
\hline
\end{tabular}

Table 3 : Assessment of third molar angulation between the study group and the control group on the right sides

\begin{tabular}{|l|c|c|c|}
\hline \multicolumn{2}{|l|}{ Angulation of $3^{\text {rd }}$ molar (Rt.) } & Control group & Study group \\
\hline \multirow{2}{*}{ Disto angular } & No. & 1 & 0 \\
\cline { 2 - 4 } & $\%$ & 2.5 & 0.0 \\
\hline \multirow{3}{*}{ Horizantal } & No. & 1 & 5 \\
\cline { 2 - 4 } & $\%$ & 2.5 & 12.5 \\
\hline \multirow{3}{*}{ Vesio angular } & No. & 14 & 13 \\
\cline { 2 - 4 } & $\%$ & 35.0 & 32.5 \\
\hline \multirow{3}{*}{ Total } & No. & 24 & 22 \\
\cline { 2 - 4 } & $\%$ & 60.0 & 55.0 \\
\cline { 2 - 4 } & No. & 40 & 40 \\
\cline { 2 - 4 } & $\%$ & 100.0 & 100.0 \\
\hline
\end{tabular}

Table 4 : Assessment of third molar angulation between the study group and the control group on the left side.

\begin{tabular}{|c|c|c|c|}
\hline \multicolumn{2}{|c|}{ Angulation of $3^{\text {rd }}$ molar (Lt.) } & Control group & Study group \\
\hline \multirow[t]{2}{*}{ Disto angular } & No. & 1 & 0 \\
\hline & $\%$ & 2.5 & 0.0 \\
\hline \multirow[t]{2}{*}{ Horizantal } & No. & 1 & 8 \\
\hline & $\%$ & 2.5 & 20 \\
\hline \multirow[t]{2}{*}{ M esio angular } & No. & 15 & 11 \\
\hline & $\%$ & 37.5 & 27.5 \\
\hline \multirow[t]{2}{*}{ Vertical } & No. & 23 & 21 \\
\hline & $\%$ & 57.5 & 52.5 \\
\hline \multirow[t]{2}{*}{ Total } & No. & 40 & 40 \\
\hline & $\%$ & 100.0 & 100.0 \\
\hline
\end{tabular}

Comparison of both groups showed no statistically significant differences between them regarding age and sex variables. The age of the subjects were matched in both the groups to eliminate the effect of growth in the retromolar area.

In the present study, no statistically significant differences were found for the third molar angulations between both the groups. But statistical significant difference was seen in relation to third molar space. It was seen that when the third molar space is less, the lower anterior crowding is more.

Measurements of third molar angulation on lateral cephalograms as in the previous studies by $\operatorname{Artun}^{30}$ (2005), Erdem7 (1998), Capelli'i2 (1991) may be biased due to differences in angulation between the superimposed contralateral images. Similar problems are present in any cephalometric study on changes in posterior tooth positions, and can only be overcome if measurements are made on 60 degree head films of right and left sides as shown by Richardson $(1970)^{18}$.

However orthopantomograhs have shown to be a reliable indicator in evaluating third molar positions as shown by Olive and Basford ${ }^{27}$ (1981), Ganss et al ${ }^{22}$ (1993) and so they were used in the present study.

The measurements used in this study was the Ganss ratio previously used by Olive and Basford to evaluate space. .2, $27^{27}$ If the ratio values are greater than 1, 70 percent of teeth would ultimately enter into the arch. Lower values were suggestive of probability of impaction. For the third molar angulation, reference angles were taken from winter's classification, in which angulation of long axis of third molar to the first or second molar was used.

In the present study a proper case selection was done wherein cases with a clear and well defined second and third molar only were selected.

The modern day patients are more aware and often question the necessity for third molar extractions. They tolerate the loss of four premolars, however are not as willing to undergo the loss of four more teeth in the form of third molars, with the end result being the loss of eight perfectly good teeth. ${ }^{18}$

It is clear from the results of the present study that anterior crowding affects the third molar space but no significant effect was shown on the third molar angulation. Hence further research is required with larger sample in different 
races on the angulation of third molar with regard to lower anterior crowding for conclusive inferences.

One limitation of the present study is that the subjects were allocated to their groups based on skeletal Class I pattern. The aetiology of crowding was not considered. This might have a bearing on the status of third molar. Further studies are required in this regard.

Further studies are also required to assess the correlation between lower anterior crowding and third molar space angulation in different skeletal malocclusions and also in different facial morphologies, including large sample size.

\section{Conclusions}

Results of the study revealed that third molar space

\section{References}

1. Yuh Hasegawa, Kazuto Terada, Ikuo Kageyama, Takashi Tsuchimochi, Fujiro Ishikawa, Sen Nakahara. Influence of third molar space on angulation and dental arch crowding. Odontology2012; $\mathrm{DOI}$ 10.1007/s10266-012-0065-2.

2. Junaid Lakhani M, Wahab Kadri, Hassan Mehdi, Houshang Sukhia, Asma Bano, Sania Yaqoob. Anterior arch crowding- a possible predictor for mandibular third molar impaction.J Ayub Med Coll Abbotttabad 2011;23(1)63-65.

3. Abu Alhaija E.S.J, AlBhairan H.M and Al Khateeb S.N. M andibular third molar space in different anteroposterior skeletal patterns. EJ02011;Vol.33, 570-576.

4. Chung How Kau et al. Evaluation of CBCT Digital Models and Traditional M odels Using the Little's Index. Angle Orthod 2010;80:435439.

5. Sidlauskas Antanas, Trakiniene Giedre.Effect of lower third molars on the dental arch crowding. Baltic dental and maxillofacial journal2006;Vol.8,No3:80-4.

6. Faraj Behbehani, Jon Artun and Lukman Thalib. Prediction of mandibular third molar impaction in adolescent orthodontic patients. Am J Orthod Dentofac Orthop 2006;130:47-55.

7. Jon Artun, Lukman Thlib, Robert M Little. Third molar angulations during and after treatment of adolescent orthodontic patients. Am J Orthod Dentofac Orthop 2006;130:47-55

8. Iwona Niedzielska.Third molar influence on dental arch crowding. EJO $2005 ; 27,518-523$.

9. Sumitra, Arundhati P Tandur.Third molars and late mandibular incisor crowding. JIOS2005;38,100-111.

10. Sandhu S,Kaur T. Radiographic evaluation of the status of third molars in the Asian-Indian students. JOral M axillofacial 2005;63(5):640-5.

11.Jon Artun, Lukman Thalib, Robert M Little. Third molar angulations during and after treatment of adolescent orthodontic patients.Eur J Orthod 2005;27:590-596.

12. Tae - Woo Kim,Jon Artun,Faraj Behbehani, and Fflavia Artese. Prevalence of third molar impaction in orthodontic patients treated nonextraction and with extraction of 4 premolars. Am J Orthod Dentofac Orthop 2003:123:138-45.

13. Faiez Hattab and Elham Abu . Radiographic evaluation of mandibular third molar eruption space. Oral Surg Oral Med Oral Path Oral Radiol Endod 1999:88:285-91

14. Erdem D, Ozdiler E, Toygar Memikoglu U and Baspinar E. third molar impaction in extraction cases treated witth the Begg technique. Eur J Orthod 1998;20:263-270. influences lower anterior crowding. Less of third molar space was seen in individuals with lower anterior crowded than in individuals without lower anterior crow ded groups.

Hence, within the limitations of this study, it may be concluded that

1. Lower anterior crowding has positive influence on the third molar space.

2. Lower anterior crowding did not have any effect on the third molar angulation.

3. Further research is required to assess the correlation between lower anterior crowding and third molar space angulation in different skeletal malocclusions and also in different facial morphologies, including large sample size in different races.

15. Friesfeld M , Drescher D, Kobe D, Schiller H. assessment of the space for the lower wisdom teeth. J Orofac Orthop 1998;59(1):17-28.

16. Ganss C, Hochban W, Kielbassa AM, Umstadt HE. Prognosis of third molar eruption. Oral Surg Oral M ed Oral Pathol 1993;76:688-93.

17. Margaret Richardson. Lower arch crowding in the young adult. Am J Orthod Dentofac Orthop 1992

18. Staggers JA, Germane N, Fortson WM . A comparison of effects of first premolar extractions on the third molar angulations. Angle Orthod 1992;62(2):135-8

19. Thomas E Southard,Karin A. Southard,Larry W.Weeda. M esial force from unerupted third molar. Am J Orthod Dentofac Orthop $1991 ;$ Vol99,No:3

20. Sewerin I, Von Wowern. Radiographic four year follow up study of asymptomatic mandibular third molars in young adults. Int Dent J 199:40:243.

21. Venta I, M urtomaa H, Turtola L, M eurman J. Assessing the eruption of lower third molars on the basis of radiographic features. British J of Oral and M axillofacial Surgery 1991;29:259-262

22. Jonas Capelli Jr. Mandibular growth and third molar impaction in extraction cases. Angle Orthod 1991;61:3:223-9.

23. Amin G Ades,Donald R Joondeph, Robert M Little,M ichael K Chapko.A long term study of the relationship of the third molars to changes in the mandibular dental arch. Am J Orthod Dentofac Orthop 1990;97,323-35

24. Carl-M agnus Forsberg. Tooth size,spacing, and crowding in relation to eruption or impaction of third molars. Am J Orthod Dentofac Orthop 1988;94:57-62.

25. Rainer Meithke,Angelika Behm.Correlations between lower incisor crowding and lower incisor position and lateral craniofacial morphology. Am J Orthod Dentofac Orthop 1988;94:231-9.

26. Margaret $\mathrm{E}$ Richardson. Late lower arch crowding in relation to primary crowding. Angle Orthod 1982. Vol 52. No.4.

27. Olive RJ, Basford KE. Transverse dentoskeletal relationships and third molar impaction. Angle Orthod 1981;51(1):41-47.

28. Mac Gregor A]. The radiological assessment of ectopic lower third molars. Ann Roy Coll Surg1979;61:105-109.

29. Richardson M. Pre eruptive movements of mandibular third molar. Angle Orthod 1978;48(3): 187-193

30. Silling G. Development and eruption of mandibular third molar and its response to orthodontic therapy. Angle Orthod 1973; 43:271-8. 